\title{
ANÁLISIS COSTO-BENEFICIO JUDICIAL/ANÁLISIS COSTO-BENEFICIO ADMINISTRATIVO: COMENTARIOS AL FALLO DE LAS CICLOVÍAS EN RANCAGUA
}

\section{MATÍAs GUILOFF TitiUN*}

Rancagua, veintidós de marzo de dos mil trece.

\section{VISTOS:}

A fs. 12 comparecen Nelly Urra Caro, domiciliada en Av. Bombero Villalobos 761, Villa Jardín Oriente; Ricardo Hernández Cortez, domiciliado en Av. Bombero Villalobos 537, Población Manzanal; Eduardo Marchant Lazo, domiciliado en Av. Bombero Villalobos 731, Villa Jardín Oriente y Mauricio Valdés Cornejo, deduciendo recurso de protección en contra de la I. Municipalidad de Rancagua, representada legalmente por su Alcalde don Eduardo Soto Romero, ambos domiciliados en Plaza Los Héroes 445, Rancagua.

Que los recurrentes son vecinos de Avda. Bombero Villalobos, y exponen que el día 18 de febrero pasado, una empresa contratada por la Municipalidad inició trabajos para la construcción de una ciclovía que estará emplazada en la vereda poniente de la calle antes mencionada, desde calle Miguel Ramírez y hasta Carretera del Cobre.

Señalan que como interesados en el emplazamiento de esas obras propusieron que la ciclovía se estableciera en el bandejón central de la avenida Bombero Villalobos, al efecto indican que de esa forma se evitarían serios riesgos como lo es que la ciclovía atravesará 72 accesos peatonales y de vehículos a las viviendas que se encuentran en esa acera, además de 15 cruces de calles y pasajes, la mayoría sin semáforos. Por su parte en el bandejón central no existen estos accesos ni cruces, y se contribuiría a eliminar malos olores, plagas de moscas y ratones por la existencia de un canal que solo ayuda a acumular basura, y a la necesaria instalación de iluminación terminando con consumo de alcohol y drogas en el sector.

Estiman que el actuar de la Municipalidad afecta las garantías de derecho a la vida y a la integridad física de las personas, y a la establecida en el numeral $8^{\circ}$ del artículo 19 de la Constitución en cuanto al deber del

Abogado, Licenciado en Ciencias Jurídicas y Sociales, Universidad Diego Portales (2003), LL.M. Columbia University (2007). Investigador del Programa de Derecho y Política Ambiental, Facultad de Derecho, Universidad Diego Portales. 
Estado de velar para que el derecho a la conservación del patrimonio ambiental no sea afectado y tutelar la preservación de la naturaleza.

Asimismo expresan que la construcción de la ciclovía en la vereda poniente es una decisión arbitraria, lo que se demuestra con todas las desventajas que ello representa y que se expusieron más arriba. En definitiva solicita se suspenda la ejecución de la obra y se realice un estudio técnico que permita determinar de forma racional y lógica el lugar de construcción de la vía en cuestión.

A fs. 35, la recurrida evacuó informe requerido en los términos que se indican a continuación.

Como cuestión previa sostiene la extemporaneidad del recurso en atención a que el contrato que da inicio a las obras de fecha 18 de diciembre pasado, y además porque el día 20 de enero de 2012, el Alcalde sostuvo una audiencia con Mario Sánchez y una delegación respecto de consultas sobre las obras de ciclovía en el sector Manzanal.

En cuanto al fondo, indica que un objetivo del municipio es el desarrollo sustentable de Rancagua, en ese entendido se incorporó al Plan Regulador comunal una planificación de la red de ciclovías, lo que se concretó a través de las modificaciones al Plan Regulador de fecha 28 de julio de 2006 y 26 de marzo de 2012. Lo que por lo demás está en armonía con los deberes y prerrogativas reguladas por la LOC de Municipalidades.

En este contexto con fecha 09 de mayo de 2012, el municipio de Rancagua recibe para su implementación de parte del Ministerio de Vivienda y Urbanismo, el estudio denominado Análisis y Desarrollo Maestro de Ciclovías, Rancagua y Machalí, que contiene un análisis económico y social de la red en cuestión, así como diseño de pavimentos, y proyectos de señalización y diseño urbano y paisajístico, dentro de lo cual la ciclovía de Avda. Bombero Villalobos está proyectada en la acera poniente de la mencionada arteria.

Por otro lado, el recurrido acota que en otras calles de la ciudad las ciclovías se han instalado en las respectivas veredas y no se han registrado estadísticamente accidentes que se deban directamente a tal disposición de las vías.

En particular, el emplazamiento de la ciclovía de Avda. Bombero Villalobos en la acera poniente, es altamente beneficioso en términos económicos para el proyecto, pero también minimiza los peligros asociados porque se trata de un sector residencial, en el bandejón central los ciclistas estarían expuestos a cruzar en ambos sentidos la vía estructurante y además al llegar a Carretera del Cobre, su angostamiento obligaría a desviar la ciclovía necesariamente a la acera poniente, sin contar además que existe un costo adicional asociado a la sinuosidad del terreno, desnivel entre calzada y bandejón, además de agregar semáforos o señales prioritarias.

Finalmente agrega que entubar el canal que se encuentra en el bandejón central es contraproducente con la declaración de zona saturada de 
la ciudad, pues el agua ayuda a humedecer el ambiente. En consecuencia solicita el rechazo del recurso con costas.

\section{CON LO RELACIONADO Y CONSIDERANDO:}

1. Que en cuanto a la extemporaneidad alegada, fundada en que el inicio de las obras data de 18 de diciembre de 2012 y en que el Alcalde de Rancagua habría sostenido una reunión con vecinos del sector para responder consultas sobre la ciclovía, con fecha 20 de enero de 2012, no existen antecedentes para establecer que los actores tomaron conocimiento del emplazamiento de la ciclovía sobre la vereda poniente en las fechas señaladas, por lo que la alegación debe ser desestimada.

2. Que la presente acción constitucional se dirige en contra de la de la decisión de la Municipalidad recurrida, de construir una ciclovía en la acera poniente de la avenida Bombero Villalobos de esta ciudad, decisión que los actores estiman arbitraria porque el emplazamiento propuesto por los vecinos del sector, sobre el bandejón central de la arteria referida, presentaría ventajas en términos ambientales, urbanísticos y de seguridad vial.

3. Que la recurrida, en su informe, ha sostenido que para adoptar la decisión sobre emplazamiento de ciclovías en la ciudad, se efectuó un estudio técnico denominado "Análisis y desarrollo Plan Maestro de Ciclovías Rancagua-Machalî”, efectuado por el Ministerio de Vivienda y Urbanismo, y que la construcción sobre la calzada poniente minimizar la contaminación ambiental, favorece la seguridad de los ciclistas, y en consecuencia, no constituye un acto arbitrario o ilegal y no afecta las garantías constitucionales de los actores.

4. Que la Corte no puede sustituir al municipio en sus facultades de gobierno local, ni en la consiguiente administración de los bienes nacionales de uso público que le competen. El acto del municipio claramente no es ilegal y tampoco es arbitrario, pues lo que la recurrente reclama se refiere en verdad a la evaluación y decisión sobre el mejor sitio para construir la ciclovia, que es justamente lo que corresponde decidir al municipio, y no a los actores ni a la Corte, habiendo entregado la Corporación, en su informe, razones suficientes para explicar su decisión, las cuales no cabe ponderar aqui, pues no se trata de si compartimos o no tales razones, sino solo si estas son tales o son apenas artilugios que oculten una sinrazón. Como este último no es el caso, más allá de la discrepancia que legitimamente puedan tener los vecinos con los argumentos municipales, estos existen, no son ilógicos ni solo aparentes, y ello basta para concluir que el acto no es arbitrario.

5. Que, desde luego, tampoco el acto amenaza derecho alguno. No puede formularse tal hipótesis por el hecho de que existan ries- 
gos de atropello, porque el riesgo del tráfico vial existe siempre y la eventual imprudencia futura de automovilistas, peatones o ciclistas es una mera especulación. Sin perjuicio de que toda la argumentación relativa a la posible amenaza a la vida e integridad física se refiere a posibles víctimas futuras indeterminadas, lo que convierte a este recurso en una suerte de acción popular, lo que no corresponde al carácter del recurso de protección.

Por estas consideraciones, lo dispuesto en el artículo 20 de la Constitución Política de la República y en el Auto Acordado de la Excelentísima Corte Suprema, sobre Tramitación del Recurso de Protección de Garantías Constitucionales, se rechaza, con costas, el deducido en lo principal de fs. 12 .

Regístrese, comuníquese y archívese en su oportunidad.

Santiago, veintisiete de junio de dos mil trece.

\section{VISTOS:}

Se reproduce la sentencia en alzada con excepción de sus considerandos tercero a quinto, que se suprimen.

\section{Y se tiene en su lugar y además presente:}

Primero: Que de los antecedentes del recurso de protección queda en evidencia que los recurrentes no cuestionan el amparo legal con que actúa el municipio en contra de cuya decisión se ejerce la acción cautelar, pues las obras destinadas a dotar de ciclovías a la ciudad de Rancagua constituyen una iniciativa que concita el apoyo de los habitantes de esa ciudad, determinación que se explica, entre otros motivos, por la necesidad de adoptar medidas frente a los altos índices de saturación de material particulado respirable existentes en la ciudad, consecuencia seguramente de la significativa congestión vehicular asociada al incremento sostenido del parque automotriz como un hecho común a todo el país.

Segundo: Que en este entendido lo que entonces se cuestiona al municipio recurrido es su proceder arbitrario, que en términos de los recurrentes se expresa en la falta de lógica y racionalidad que posee la decisión adoptada por el municipio al definir el lugar en el que finalmente se ubicará la ciclovía aludida. Consecuentemente con el apoyo que suscita en dichos recurrentes la construcción de la mejora vial que motiva la controversia con el municipio, lo que se pide en la acción cautelar no es la paralización definitiva de las obras de construcción, sino su suspensión, a la espera de realizar un estudio técnico que permita determinar bajo criterios amplios, de forma racional y lógica, el mejor lugar para su construcción. 
Tercero: Que lo referido obliga a esta Corte a reparar en los fundamentos y motivaciones de la decisión alcaldicia, única forma de dilucidar si su actuación ha sido contraria a la lógica y la razón, en los términos que lo denuncian los recurrentes.

Cuarto: Que como lo consigna el informe agregado en su oportunidad y que dice relación con los "Planos de Estudio del Proyecto Ciclovías Rancagua y Machalî", cuya elaboración estuvo a cargo del Ministerio de Vivienda y Urbanismo, una obra civil de estas características es siempre factible de construir, reduciéndose su complejidad a un problema de costo.

Este tribunal no ignora, desde luego, la necesidad de una optimización del uso de los recursos municipales y públicos, con el propósito de generar el efecto multiplicador que mejore la calidad de vida, en este caso, de los vecinos de la comuna y específicamente del sector en el cual se emplazará la ciclovia, de la forma como alude a ello el informe de la autoridad recurrida, a fojas 43.

Sin embargo, es precisamente la calidad de vida de los recurrentes la circunstancia que fuerza a reparar en las motivaciones de la decisión impugnada por esta vía.

Quinto: Que de acuerdo al mérito de los documentos agregados a estos autos, no cuestionados por los litigantes, constituye un hecho indesmentible que la acera poniente de la avenida Bombero Villalobos constituye un sector consolidado, en términos de accesos a las viviendas emplazadas y de antejardines vegetados, lo que denota esfuerzo y preocupación sostenidas de los vecinos del sector en orden a procurarse un lugar grato y confortable para su vivienda y entorno. Por el contrario, en el bandejón central existente en esa arteria, que corre paralelo a una y otra de sus aceras, se observa un paraje de características y condiciones por completo opuestas y diferentes, un área prácticamente carente de vegetación, sin ninguna mejora, en virtual abandono, con abundantes desperdicios y basura, en medio de la cual se aprecia un colector de agua, seco y vacío, que al parecer solo da margen a un acopio de elementos de desecho en su interior.

Sexto: Que de acuerdo a lo consignado, para esta Corte resulta evidente que en el plano económico una adecuada asignación de los recursos del municipio importará el que la construcción de la mejora vial de que se trata provoque el menor dańo posible en el entorno de su emplazamiento. Su construcción en el bandejón señalado no solo no obligará a resarcimiento alguno, sino que claramente constituirá una instancia útil para convertir su área en un lugar provechoso para la comuna, sacándola del abandono en el que actualmente se encuentra.

Séptimo: Que no tendrían asidero, en ese predicamento, las prevenciones que se formulan en cuanto a que el emplazamiento de la ciclovía obligaría a entubar el curso del canal allí existente, con el negativo im- 
pacto que produciría en las medidas destinadas a combatir la polución del aire en la ciudad, si, como se aprecia de las imágenes fotográficas agregadas al recurso, se trata más bien de un curso de agua ocasional, que permanece al parecer la mayor parte del tiempo seco, sin desplazamiento alguno del líquido en su interior, conclusión que se ve corroborada con lo que da cuenta el documento agregado a fojas 47, consistente en un certificado expedido por la Asociación de Canalistas, Canales San Pedro, Población y Derivados, que desconoce su pertenencia al rol de usuarios de la citada asociación. Por lo demás, no hay en el proceso elemento o antecedente alguno que haya manifestado con elementos técnicos la inconveniencia e incluso el peligro de encauzar o cerrar tal canal.

Por el contrario, la concesionaria de los servicios sanitarios de la Sexta Región, ESSBIO S.A., por medio de comunicación agregada a fojas 51, advierte de la necesidad de realizar obras de protección de una válvula de gran tamaño, que enfrentaría la construcción de la citada ciclovía en el lugar en el cual se ha resuelto por el municipio, constituyéndose esta observación en un argumento técnico adicional que no fue indagado en su momento por el recurrido.

Octavo: Que consecuencia de lo razonado es que este tribunal estima que las obras destinadas a emplazar la ciclovía mencionada en el lugar determinado por el municipio envuelve un acto arbitrario, que conlleva el sacrificio de lo que con esfuerzo y dedicación los vecinos recurrentes han consolidado a lo largo de los ańos, en desmedro de recuperar una franja de terreno abandonada y huérfana de toda preocupación y mejora, siendo una indesmentible muestra de irracionalidad, lo que lleva a esta Corte a la necesidad de otorgar la protección demandada.

Noveno: Que así el actuar de la recurrida vulnera la garantía del artículo 19 numeral 2 de la Carta Fundamental al resolverse la construcción de la ciclovía de una forma diversa de lo que ha sido en otros lugares, esto es privilegiando el bien común de la comuna y de cada uno de sus habitantes.

Y de acuerdo a lo que establece el numeral 2 del artículo 19 de la Constitución Política de la República y el Auto Acordado sobre la materia, se revoca la sentencia apelada de fecha veintidós de marzo último, escrita a fojas 62 , y se declara que se acoge el recurso de protección intentado a fojas 12, ordenándose la suspensión de las obras de construcción de la ciclovía mientras no se realicen los estudios de factibilidad técnica necesarios que demuestren fehacientemente que la construcción de la ciclovía en el lugar que los recurrentes recomiendan adolece de inconvenientes graves que la tornen inviable.

Acordada con el voto en contra del Ministro señor Pierry y del Abogado Integrante señor Pfeffer, quienes fueron de parecer de confirmar la sentencia en alzada en virtud de sus propios fundamentos.

Redacción a cargo del Ministro señor Muñoz y la disidencia sus autores. 


\section{1) Comentario}

Las sentencias de la Corte de Apelaciones y Suprema recaídas en el Recurso de Protección presentado por un grupo de vecinos de la ciudad de Rancagua en contra de la decisión de la Municipalidad respecto al emplazamiento de una ciclovía son interesantes por varias razones. En primer lugar, porque ponen de manifiesto una vez más el sitial predominante que ha adquirido en nuestro sistema legal el Recurso de Protección como mecanismo contencioso administrativo. Lo son, luego, porque ilustran el dilema eficacia/legalidad que atraviesa al derecho administrativo. En términos sencillos, este dilema se refiere al permanente conflicto entre la ineludible responsabilidad de los órganos de la administración del Estado de actuar para proteger los intereses de la colectividad -eficacia- y los controles a los que deben quedar sujetas las decisiones que se adopten para este propósito -legalidad. Por último, estas decisiones son también de interés en la medida que ilustran los contornos de la arbitrariedad en tanto estándar de control del ejercicio de las potestades administrativas. En este último punto se centrará el análisis que realizaré en las próximas líneas.

Como se aprecia en el considerando segundo de las decisiones de la Corte de Apelaciones de Santiago y la Corte Suprema, respectivamente, en ningún momento se alega en este caso que la recurrida haya cometido ilegalidad alguna; lo que se plantea, concretamente, es que su decisión relativa al emplazamiento de la ciclovía es arbitraria. De acuerdo a los recurrentes, la arbitrariedad vendría dada porque al adoptar su decisión la Municipalidad no hizo una adecuada evaluación relativa de los costos y beneficios de las diversas alternativas de emplazamiento. Para determinar si en este caso hubo o no una actuación arbitraria, ambas Cortes revisan la fundamentación de la decisión impugnada. La Corte Suprema, sin embargo, lo hace sometiendo a la decisión a una revisión mucho más intensa que la realizada por el tribunal de primera instancia. Pero eso no es todo lo que la Corte Suprema hace; al mismo tiempo, obrando con los antecedentes aportados en el recurso, hace $s u$ propia evaluación comparativa de los costos y beneficios de las dos alternativas de emplazamiento. Habiendo realizado este ejercicio, llega a la conclusión que la alternativa propuesta por los recurrentes resulta más ventajosa que la determinada por la Municipalidad. En base a esta consideración puede estimar, como en definitiva lo hace, que la decisión de la Municipalidad en cuanto al emplazamiento de la ciclovía carece de fundamentación y es por tanto arbitraria.

La aproximación utilizada por la Corte Suprema en este caso ilustra los peligros que se generan en el tránsito desde el análisis de la fundamentación al de la proporcionalidad para evaluar si una medida es arbitraria o no. Evidentemente, una condición básica con que debe cumplir toda decisión de un órgano administrativo es estar dotada de un fundamento racional -de ahí la repetida frase que lo no fundamentado es por sí solo 
arbitrario $^{1}$. Pero el que una decisión exprese las razones que la fundamenten no elimina la posibilidad de que sea arbitraria; si aparecen fundadas en el capricho, esas mismas razones pueden llevar a que el acto en cuestión se estime arbitrario. En términos sencillos, la idea es que no basta con que el órgano explicite las razones que fundamentan su decisión para dar por satisfechas las exigencias del estándar de la arbitrariedad. Para ello se requiere, además, que esos fundamentos lleven al órgano de control a concluir que la decisión adoptada, aun cuando no la mejor en $s u$ perspectiva, es al menos una que razonablemente se pudo adoptar en base a ellos.

Es ahí donde está el problema metodológico del análisis de arbitrariedad que realiza la decisión de la Corte Suprema. Esta, en definitiva, acoge el Recurso porque no comparte la evaluación de los costos y beneficios realizada por la Municipalidad al adoptar la decisión de emplazamiento. En su parecer, adoptar una decisión respecto al emplazamiento que implique el sacrificio de "lo que con esfuerzo han construido los vecinos a lo largo de los años", en vez de decidir situarla allí donde no se les causará ese perjuicio y además se solucionará una situación de abandono y descuido -en el bandejón central-, envuelve una irracionalidad y consiguientemente una arbitrariedad. Pero, como se ha dicho, el hecho que la decisión que se adopte genere consecuencias nocivas no la torna por sí sola en arbitraria. Para llegar a esta última conclusión habría que tener certeza en cuanto a que los daños que se generan por la decisión de emplazamiento exceden a los beneficios que de ella se derivan.

Todo esto, salvo que se entienda que hay arbitrariedad allí donde la decisión administrativa incumple un estándar de proporcionalidad estricta, de manera tal que lo único que se torna relevante es si la alternativa de emplazamiento por la que finalmente se optó es la que acarrea menores costos para un determinado derecho ${ }^{2}$. Esa determinación supone un alto nivel de información y difícilmente podrá arribarse a ella sin que previamente se haga un análisis de la bondad o mérito de la decisión administrativa ${ }^{3}$. El propio fallo de la Corte Suprema ilustra nítidamente este último punto al señalar que "para esta Corte resulta evidente que en el plano económico una adecuada asignación de los recursos del municipio importará el que la construcción de la mejora vial de que se trata provo-

Véase, Corte Suprema, 16 de mayo de 1991, Rol No 16.790, Rosas Díaz y otros con Director de la Policía de Investigaciones de Chile, Revista de Derecho y Jurisprudencia, tomo LXXXVIII, No 2, 1991, segunda parte, sección quinta, pp.123-124 (citando a FernándeZ, ToMás Ramón (I99I) Arbitrariedad y Discrecionalidad. Madrid: Editorial Civitas, 144 pp., pp. 106-107.

2 Véase Craig, Paul (1999) Administrative Law. Londrés: Sweet \& Maxwell, 681 pp., p. 591.

3 La literatura sobre el control judicial de los actos de la administración reconoce lo difícil que resulta controlar la racionalidad de una decisión, sin realizar algún mínimo análisis acerca de cómo el órgano administrativo debió haber ejercido su discreción para el caso en revisión. Véase Craig (1999) 579-580. 
que el menor daño posible en el entorno de su emplazamiento". Solo una vez que la Corte ha adoptado esa decisión de mérito -cual es la adecuada asignación de los recursos municipales- es que puede afirmar que construir en el bandejón central no solo no implica la necesidad de otorgar resarcimiento alguno, sino que también aparece como una instancia útil para convertir el abandonado bandejón central en un lugar provechoso para la comuna.

Como se puede apreciar, lo que guía la decisión de la Corte es una determinación en cuanto a la adecuada asignación de los recursos de la Municipalidad. En otras palabras, su juicio se basa en la evaluación que ella hace de la eficiencia de la decisión municipal. Ilustrativamente, detrás del argumento que la ciclovía debe localizarse allí donde no genere perjuicio individual alguno se encuentra la clásica concepción de eficiencia defendida por Wilfredo Pareto. En conformidad a esta, una modificación relativa a la asignación de recursos existente es eficiente cuando aumenta el bienestar general sin que genere perjuicio alguno ${ }^{4}$. Sin embargo, por más que la teoría económica neoclásica respalde la manera en que la Corte plantea el problema, el punto es que las Cortes no están para adoptar estas decisiones de eficiencia, ni menos para imponerlas sobre aquellas de los órganos constitucionalmente legitimados para ello -en este caso, la Municipalidad-.

Podría argumentarse que allí donde se toma una decisión de política pública que genera algún tipo de sacrificio, en circunstancias que pudo perfectamente haberse adoptado otra que no implique sacrificio alguno, habría irracionalidad y por tanto arbitrariedad. Si bien esto es cierto, para admitirlo sin más habría que tener certeza con respecto a que los costos asociados al curso de acción que no genera perjuicio alguno son inferiores al de aquel que sí genera este perjuicio. Ya que si son superiores, y la Municipalidad opta igualmente por adoptarlo para no causar perjuicio individual alguno, la comunidad afectada podría perfectamente estimar que el respectivo órgano está adoptando un curso de acción irracional, por cuanto los escasos recursos municipales que deben ser utilizados para cumplir con los diversos cometidos que la Ley le asigna a las municipalidades (la mantención del aseo y ornato, de los bienes nacionales de uso público y de las áreas verdes de la comuna, entre otras) no estarían siendo utilizados de la manera más costo-eficiente posible. El

\footnotetext{
La propia evolución de la teoría económica ilustra lo difícil que es sujetar la asignación de recursos al estándar de Pareto. La rigidez del esquema de Pareto, dada por la necesidad de resarcir a aquellos que se verán afectados por la nueva asignación de recursos, llevó a que fuera sustituido por aquel que en su momento ofrecieron Kaldor y Hicks, en conformidad al cual basta que las ganancias que se generen con la nueva asignación excedan a los costos para concluir que esta es eficiente. Una buena descripción y crítica de estas nociones de eficiencia en Coleman, Jules (2003) Markets, Morals and the Law. Oxford: Oxford University Press, 393 pp., pp. 71-72 y 84 .
} 
punto es que difícilmente podrá una Corte a través del proceso judicial conocer todos los costos asociados a un curso de acción y a sus potenciales alternativas; toda la información con que cuenta para estos propósitos es aquella que aportan las partes del proceso, y debe filtrarla de forma tal que pueda expresarla en su decisión definitiva en términos de afectación a derechos. Esto difiere de lo que sucede en sede administrativa, donde se toman en consideración muchas otras variables junto con las eventuales afectaciones a derechos, y la decisión del órgano no está constreñida por las peticiones de las partes.

Debe considerarse adicionalmente que la Corte conoce de esta actuación administrativa a través del Recurso de Protección. Como en esta acción constitucional es bastante poca la información y los elementos de prueba que el tribunal puede tener a la vista al momento de decidir, es muy difícil que pueda concluir que ha habido una mala asignación de recursos. De adoptarse esa conclusión, ella va a estar probablemente afectada por lo que los economistas denominan la falacia de Nirvana: concluir que una opción que se ha adoptado en la realidad es mala utilizando como parámetro de comparación una alternativa ideal ${ }^{5}$. Que no se malinterprete el argumento; el punto no es que al evaluar si una determinación de un órgano administrativo es o no arbitraria, la Corte se debe limitar a revisar si se encuentra fundamentada. Como lo he señalado antes, una decisión, aunque fundamentada, puede igualmente ser irracional y por ello arbitraria. El argumento es más bien que al controlar la arbitrariedad de una determinación de la administración, y sobre todo cuando conoce de ella a través del Recurso de Protección, una Corte debe limitarse a verificar que esta sea una de entre las varias alternativas que a la luz de los antecedentes el órgano respectivo pudo adoptar. Es que cuando conoce de una actuación administrativa a través del Recurso de Protección, una Corte no se encuentra suficientemente equipada, por carecer de la información suficiente, para adoptar cualquier determinación que vaya más allá de esto.

En suma, el caso ilustra algo que es más o menos evidente cuando las Cortes controlan la arbitrariedad de una actuación administrativa: lo probable que resulta que se termine realizando análisis de mérito. No solo eso, aún para aquellos que no les incomoda que para hacer un análisis de proporcionalidad las Cortes evalúen el mérito de la decisión, el caso ilustra cómo el Recurso de Protección no dota a las Cortes de los elementos necesarios para hacer con un mínimo de rigor esa tarea. Hay que decirlo claramente: una vez que se da el tránsito desde el análisis de fundamentación al de proporcionalidad, es difícil que una Corte no termine impo-

Esta denominación en Demsetz, Harold (1969) "Information and Efficiency: Another Viewpoint". Journal of Law \& Economics, Vol 12, No 1, pp. 1-22, pp. 1-2. 
niendo su propio y teórico análisis costo/beneficio a aquel de los órganos democráticamente legitimados. Es por esto que el estándar de escrutinio propio del control de arbitrariedad debe situarse en un punto intermedio entre el deferente análisis de fundamentación y el intrusivo examen de proporcionalidad. Solo así, me parece, podemos cumplir con el objetivo del derecho administrativo -la satisfacción de las necesidades colectivassin que ello implique renunciar al control de los actos de la administración. 